Case Reports

\title{
Abrus Precatorius Induced Hemorrhagic Colitis
}

\author{
${ }^{1}$ Rajeshkumar Ganesan and ${ }^{2}$ Rajalakshmi Ettiyan \\ ${ }^{I}$ Gastroenterology, Sri Venkateswara Medical College and Research Centre, India \\ ${ }^{2}$ Internal Medicine, Indira Gandhi Medical College and Research Institute, India
}

Article history

Received: 02-07-2015

Revised: $15-07-2015$

Accepted: 11-08-2015

Corresponding Author: Rajeshkumar Ganesan

Gastroenterology, Sri

Venkateswara Medical College and Research Centre, India

E-mail: rajeshganesan80@gmail.com

\begin{abstract}
Abrus Precatorius commonly known as Rosary bead or Kundumani (Arena, 1986) is an irritant poison affecting almost all major systems of the body with more damage to the gastrointestinal system. The mortality rate is 10 to $15 \%$ for a lethal dose of just $1-2$ crushed seeds. Following is the case report of hemorrhagic colitis due to the ingestion of a toxic dose of ABRUS seeds (Reedman et al., 2008). Sigmoidoscopy was done to document the hemorrhagic colitis. Client was treated as severe colitis with intra venous antibiotics, intravenous steroids; Oral Mesalamine, Intra venous Pantaprazole and IV fluids. Despite consuming a large amount of the toxin, our client survived.
\end{abstract}

Keywords: Abrus Precatorius, Hemorrhagic Colitis, Severe Colitis

\section{Introduction}

abrus Precatorius commonly known as Rosary bead or Kundumani (Arena, 1986) is an irritant poison affecting almost all major systems of the body with more damage to the gastrointestinal system. Oral ingestion of whole seeds often does not produce serious illness since the shell protects the toxin from digestion (Shih and Goldfrank, 1998). The mortality rate is 10 to $15 \%$ for a lethal dose of just 1-2 crushed seeds. The damage is done by a Toxalbumin called ABRIN concentrated more in the seeds and released on crushing (Reedman et al., 2008). Following is the case report of hemorrhagic colitis due to the ingestion of a toxic dose of ABRUS seeds (Reedman et al., 2008). Sigmoidoscopy was done to document the hemorrhagic colitis. Client was treated as severe colitis with intra venous antibiotics, intravenous steroids; Oral Mesalamine, Intra venous Pantaprazole and IV fluids. Despite consuming a large amount of the toxin, our client survived.

\section{Case Report}

A 25 year old female was brought to our casualty with alleged history of consuming a handful of crushed Kundumani seeds (Abrus Precatorius) mixed with water as single intake with suicidal intention about $10 \mathrm{~h}$ back.

On day 1, she had a history of multiple episodes of vomiting after 3-4 $\mathrm{h}$ of ingestion which was not blood stained. No history of abdominal pain, fever, dyspnoea, melena and bleeding per rectum at the time of admission.
There was no significant history of any ailments, substance abuse or medications in the past.

On general examination, she was conscious and oriented and there were no pallor, Icterus, Cyanosis, Clubbing, Lymphadenopathy and Pedal edema. Her vitals were blood pressure-100/70 $\mathrm{mm} / \mathrm{Hg}$, Pulse $62 / \mathrm{min}$ which was regular and normal in volume, Respiratory rate -20 breaths $/ \mathrm{min}$ and afebrile. On systemic examination, per abdomen- soft, no tenderness and normal bowel sounds were heard. Other system examination was normal.

Stomach wash was given in the casualty till clear fluid was obtained. Activated charcoal $(50 \mathrm{gm})$ was given through Ryles tube. Blood sample was taken and sent for routine investigation. She was started on intra venous fluids and inj. Pantaprazole and shifted to intensive care unit for monitoring.

Routine investigation revealed Hemoglobin-12 g\%, Total count-6700 cells/cu.mm, DC -Neutrophils: 77\%, Lymphocytes: $20 \%$, Eosinophils: $03 \%$, Monocytes: $0 \%$, Basophils: $0 \%$, Hematocrit $-34 \%$, Platelet count -1.84 lakhs/cu.mm, Blood group -B-positive, Prothrombin time $-15.2 \mathrm{sec}$ ( control $-13.5 \mathrm{~s}$ ) INR $-1.2 \mathrm{sec}$. Blood glucose $(\mathrm{R})-111 \mathrm{mg} \mathrm{dL}{ }^{-1}$. Serum Bilirubin: Total -1.0 $\mathrm{mg} \mathrm{dL}{ }^{-1}$, Direct $-0.7 \mathrm{mg} \mathrm{dL}{ }^{-1}$, Indirect $-0.3 \mathrm{mg} \mathrm{dL}^{-1}$, Total protein $-6.0 \mathrm{~g} \%$, Albumin $-3.7 \mathrm{~g} \%$, Globulin -2.3 g\%, AST(SGOT) -34 IU/L, ALT (SGPT) - $17 \mathrm{IU} / \mathrm{L}$, ALP- $61 \mathrm{IU} / \mathrm{L}$, Urea- $16 \mathrm{mg} \mathrm{dL}{ }^{-1}$, S. Creatinine $-0.6 \mathrm{mg}$ $\mathrm{dL}^{-1}$, Sodium $(\mathrm{mmol} / \mathrm{L})-137$, Potassium(mmol/L)- 3.6, Chloride $(\mathrm{mmol} / \mathrm{L})-106$. Urine routine was within normal limits. Figure 1 showed the Electro cardiogram at the time of admission. 


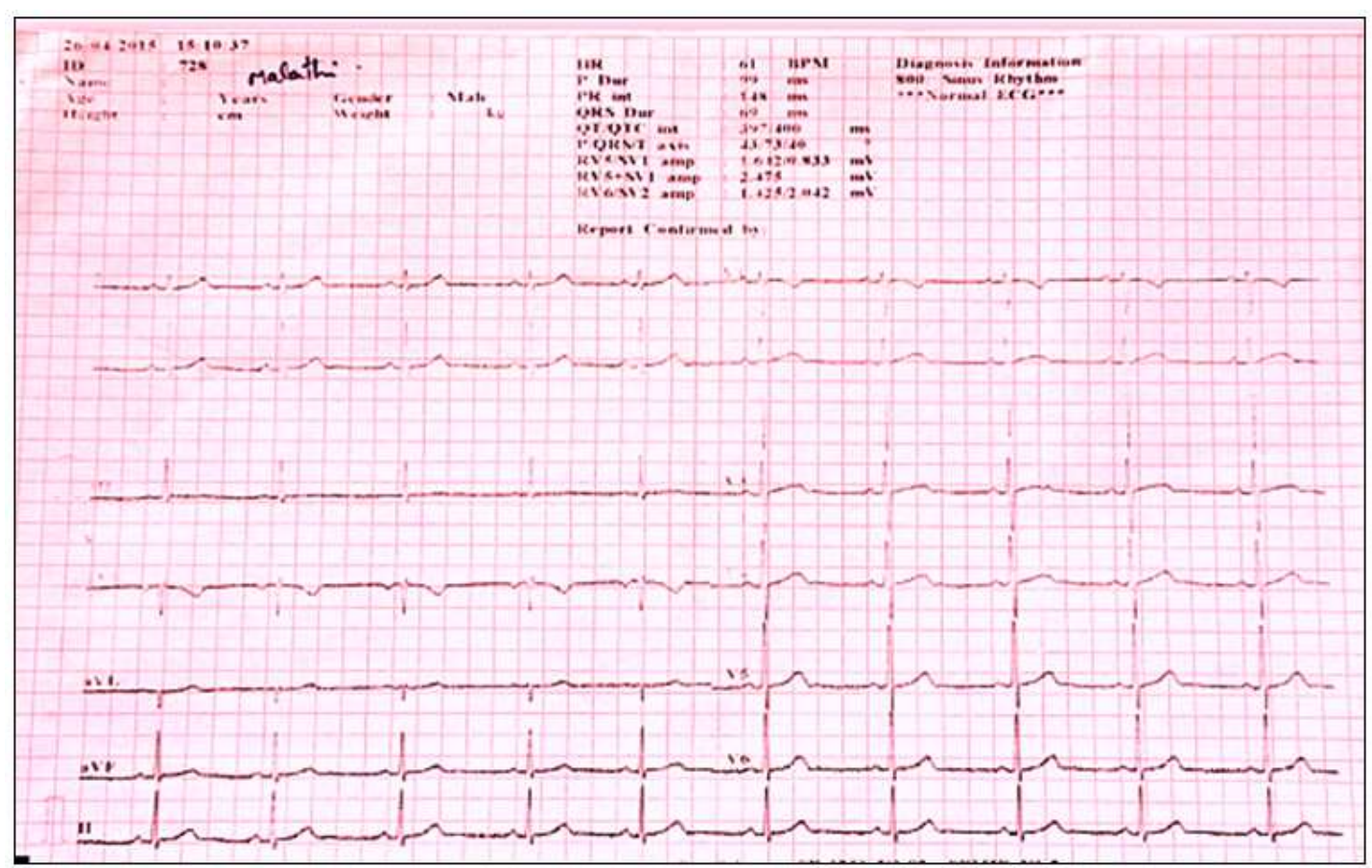

Fig. 1. ECG at the time of admission

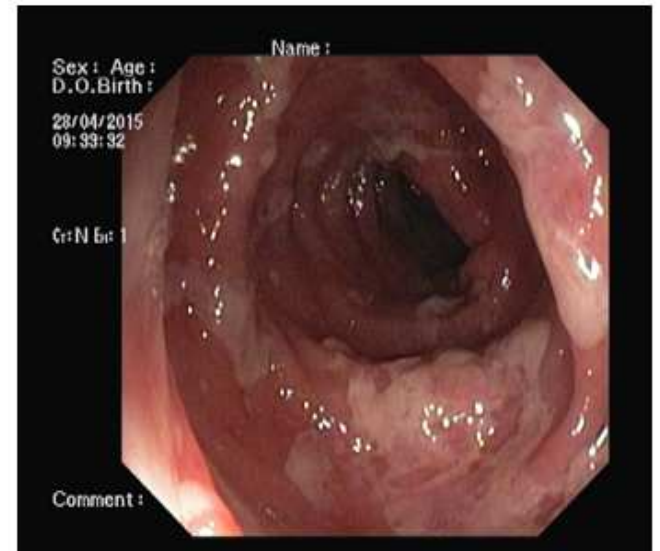

(a)

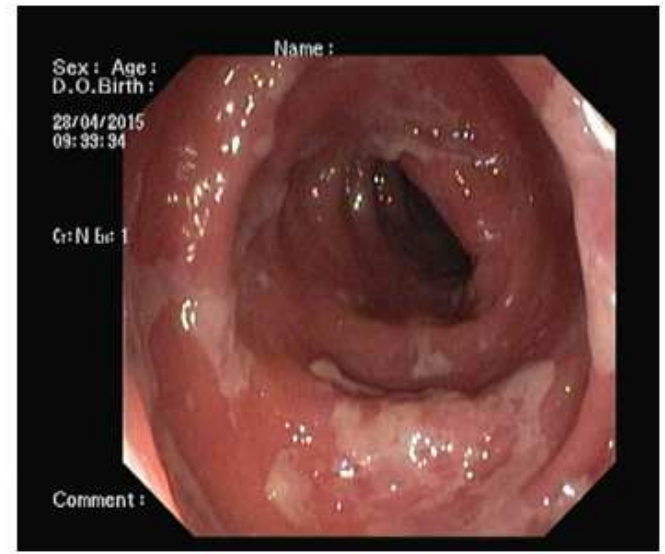

(b)

Fig. $2 \mathrm{a}$ and $\mathrm{b}$. Transverse colon-Diffuse inflammation with sloughing with moderate friability

On day 2, she developed abdominal pain which was diffuse, mild to moderate intensity and associated with loose stools, 20 episodes/day, Watery in consistency and moderate volume. She was kept nil per oral in view of diffuse abdominal pain, expected severe colitis and fear of perforation.

On day 3, she developed blood stained loose stools, 10-15 times per day, 10 to $15 \mathrm{~mL}$ of frank blood with each episode and stool routine investigation was pale red in color, liquid in consistency, plenty of RBC's, few mucus, no pus cells and no ova and cyst. With further progression of symptoms simulating hemorrhagic colitis, sigmoidoscopy was planned in the unprepared colon.
Sigmoidoscopy was done with minimal air inflation with intra venous sedation, passed upto mid transverse colon. It showed moderate to severe mucosal ulceration with sloughing, more confined to transverse and desending colon; diffuse erythema noted in the sigmoid colon and the rectum was normal. Intensity of colitis was more towards the proximal colon than the distal colon. The following pictures were the sigmoidoscopy images. Figure $2 \mathrm{a}, \mathrm{b}$ and $3 \mathrm{a}, \mathrm{b}$ showed the Transverse colon and Descending colon with diffuse inflammation with sloughing with moderate friability. Figure $4 a$ and $b$ showed the Sigmoid colon with diffuse erythema with mild friability. Figure 5a and b showed the Rectum with normal vascular and mucosal pattern. 


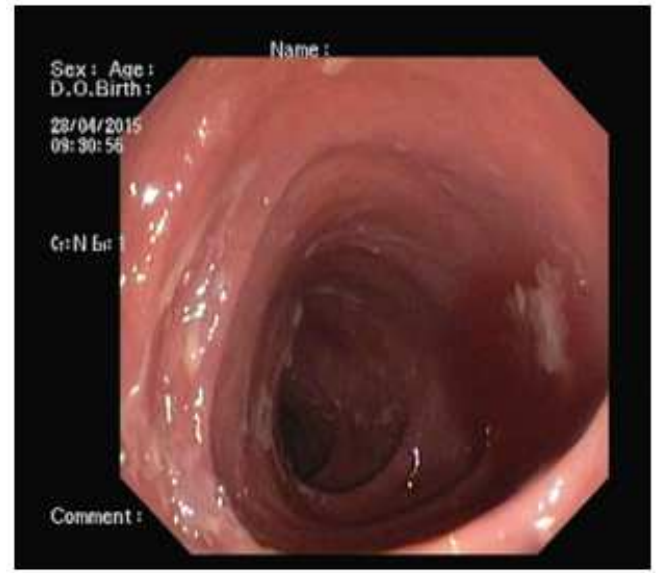

(a)

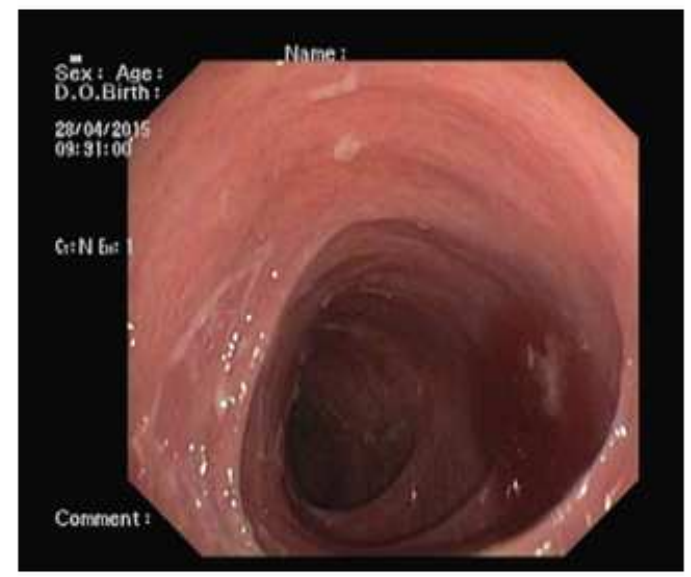

(b)

Fig. 3a and b. Descending colon- Diffuse inflammation with sloughing with moderate friability

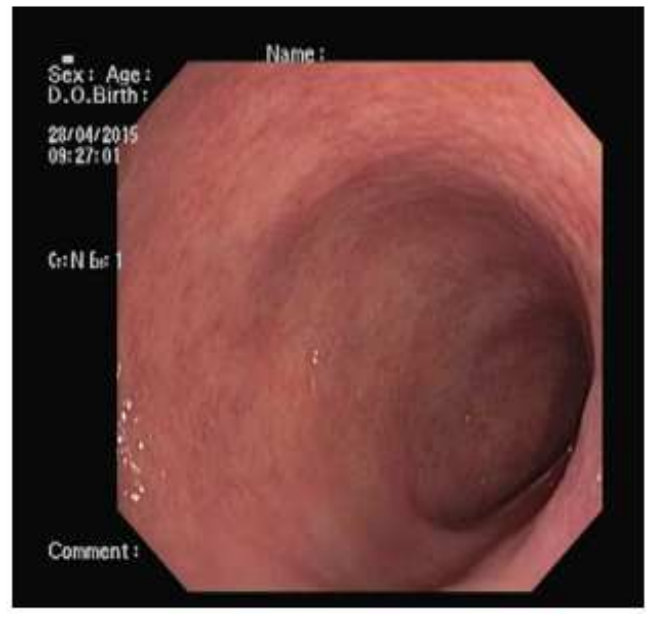

(a)

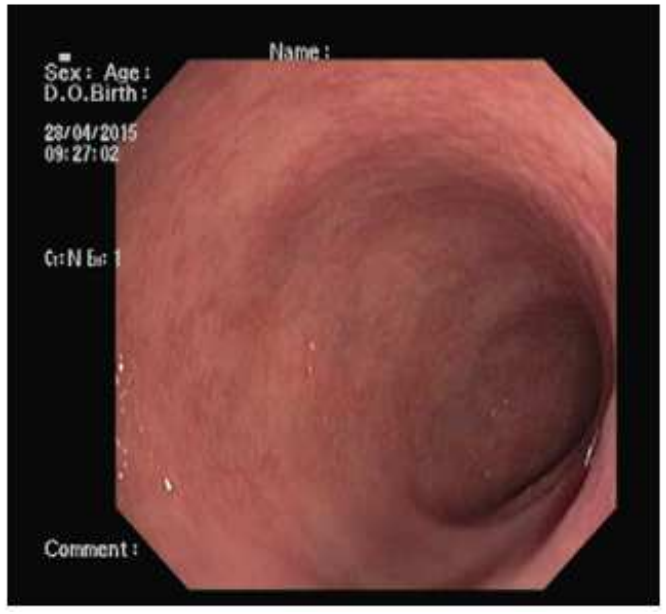

(b)

Fig. 4a and b. Sigmoid colon- Diffuse erythema with mild friability

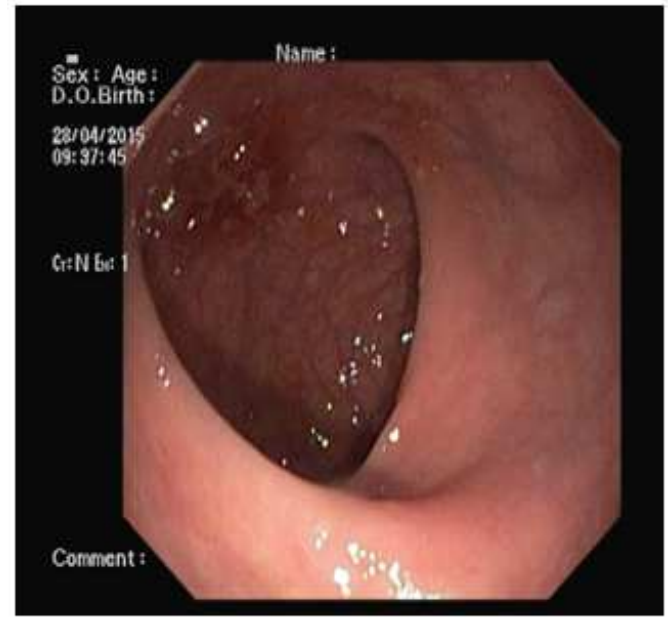

(a)

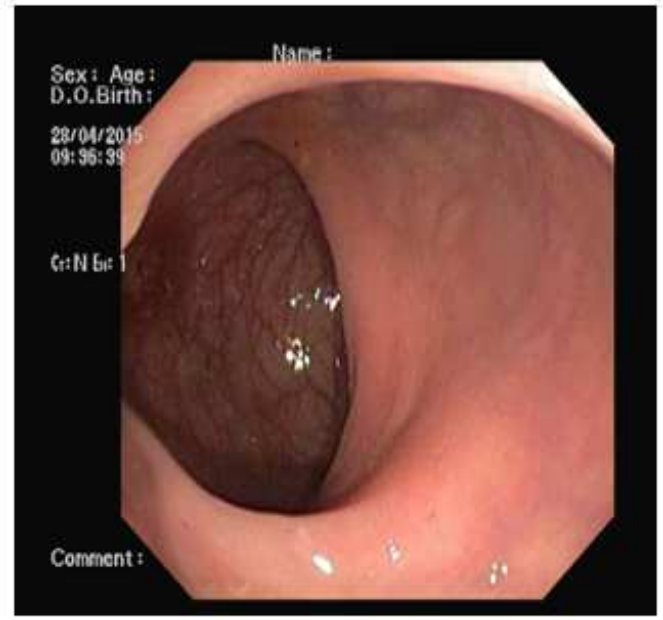

(b)

Fig. 5a and $\mathrm{b}$ rectum-normal vascular and mucosal pattern 


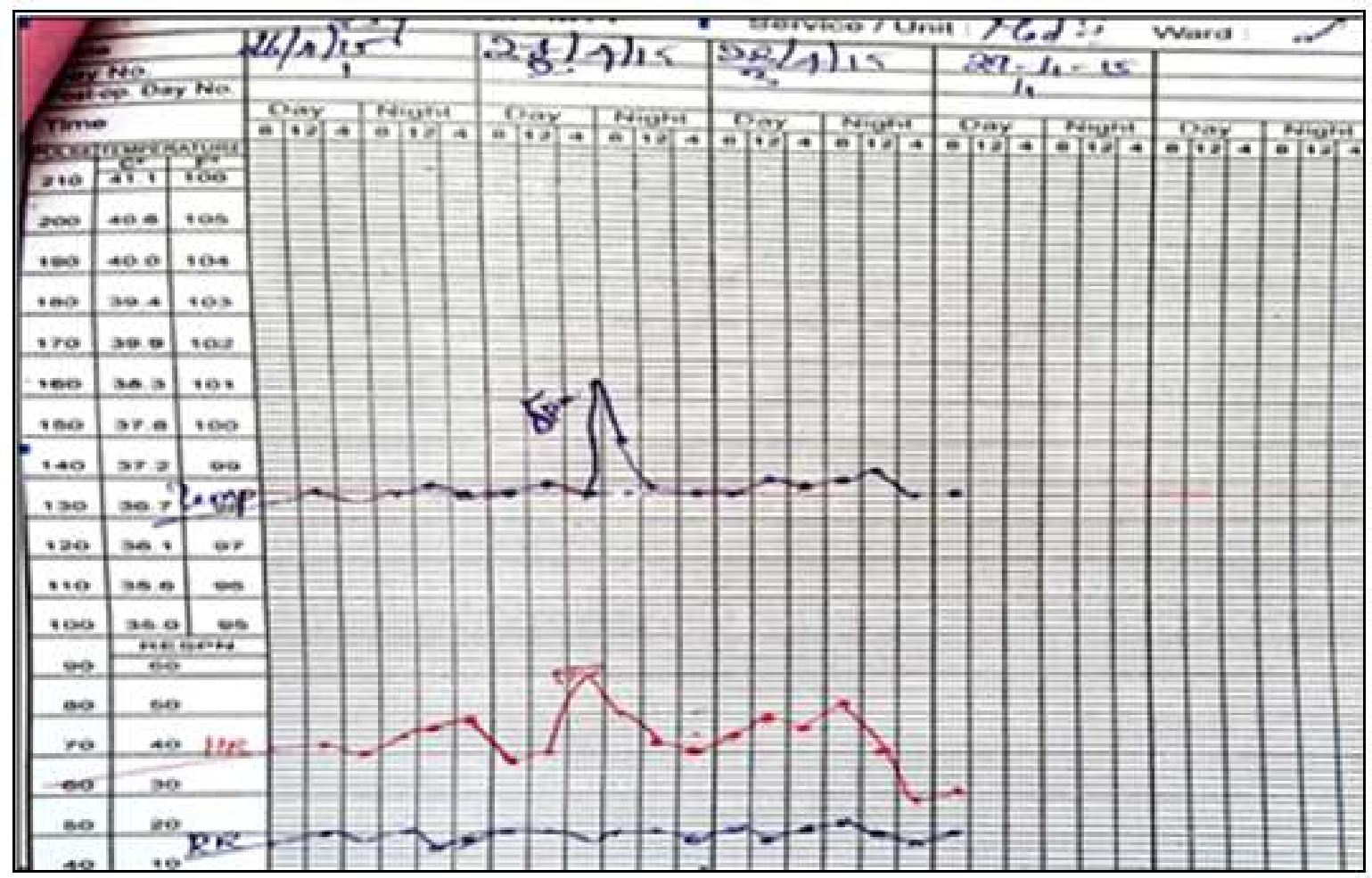

Fig. 6. Showed vitals monitoring

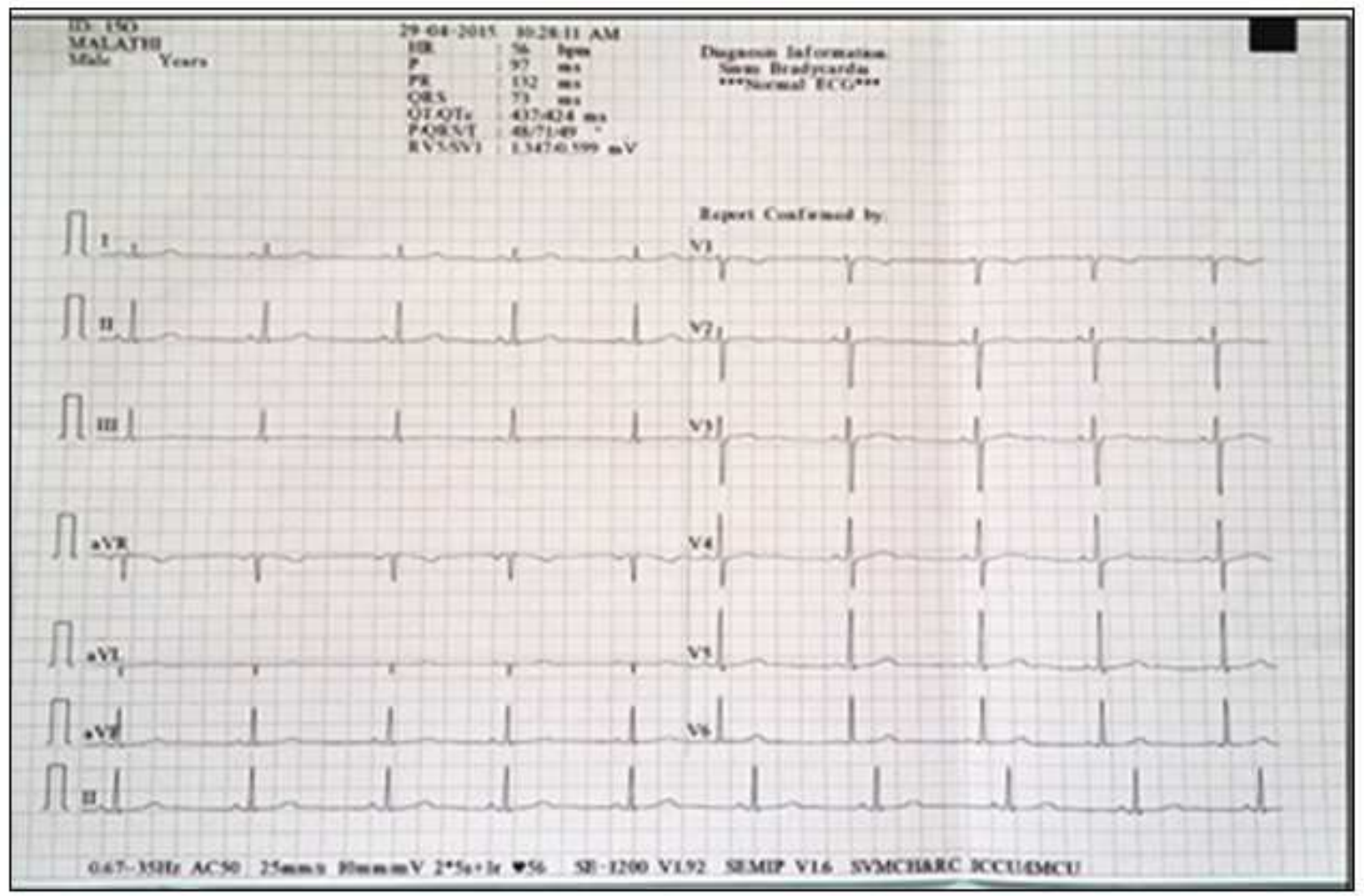

Fig. 7. Showed ECG on day 4 with sinus Brady Cardia 
Under vigilant monitoring, she was started on Inj.Hydrocortisone (100 mg) intravenous 8th hourly, Tab.Mesalamine $800 \mathrm{mg}$ thrice daily with sips of water, Inj.cefaperazone and sulbactam $1.5 \mathrm{~g}$ intra venous 12 th hourly, Inj.metronidazole $500 \mathrm{mg}$ intra venous 8th hourly, Inj.pantoprazole $40 \mathrm{mg}$ intra venous 12 th hourly. Liberal amounts of intravenous fluids were given according to the hydration status (according to blood pressure and urine output).

On day 4, in addition to the gastrointestinal symptoms, she developed sinus bradycardia which was probably due to the toxic effect to Cardio vascular system which was showed in Fig 6 and 7

On day 5, she showed an improvement within $24 \mathrm{~h}$ of therapy by means of less intensity abdominal pain, reduced episode of loose stools and no episode of hematochezia and vitals were stable.

On day 6, Oral liquids followed by soft diet was started within $12 \mathrm{~h}$ of span and shifted to general ward. Psychiatric counseling was obtained.

On day 7, all the injections were stopped and started on Oral Pantaprazole, Syrup. Sucralfate, Probiotic capsules and Multi vitamin tablets.

On day 8, she was discharged with above medications and reviewed after 3 days. On day12, she was doing well and vitals and all repeated routine investigations were within normal limits.

\section{Discussion}

This is a case report of hemorrhagic colitis due to Abrus Precatorius poisoning with sigmoidoscopy pictures.

According to (Davies, 1978) Symptoms can sometimes be delayed for 1-3 days after ingestion and the clinical course can last up to 10 days. In this case, symptoms were started on day 2 with watery diarrhea and progressed to hematochezia on day 3.

According to (Shih and Goldfrank, 1998), Typical GI symptoms include nausea, vomiting and diarrhea, resulting in more serious poisoning with severe dehydration and death (Shih and Goldfrank, 1998). In this case, in addition to these symptoms, frank hematochezia was noted.

According to (Dickers et al., 2003), the estimated human fatal dose is 0.1 to $1 \mathrm{microgram} / \mathrm{kg}$ and ingestion of one to two crushed seeds is sufficient to cause death. In this case, despite of consuming a large amount of the toxin (handful of crushed seeds) with toxic symptoms (frank hematochezia), our client survived. This could be attributed to the rate of absorption of the toxin and the early intervention done.

According to (Pillay et al., 2005), treatment of Abrus poisoning comprises timely decontamination (by stomach wash) and supportive measures and there is no antidote. Abrin, toxic component of Abrus precatorious, is an irritant poison which cause severe inflammation with erosions which mimics the colonoscopy picture of Ulcerative colitis. In this case, our client presented with hemorrhagic colitis with frank hematochezia. Hence, along with the supportive measures, we tried the drugs used in severe ulcerative colitis and our client responded well to the treatment. Hence, in Abrus precatorious poisoning with hemorrhagic colitis, intra venous antibiotics, steroids, pantaprazole and oral mesalamine may be useful. But it should be proved in large series.

No literature documented the colonoscopy picture of hemorrhagic colitis caused by Abrus precatorious. But, in this case, we were able to document the colonoscopy findings. Large intestine is the predominant organ affected by hemorrhagic colitis and also the proximal colon severely affected than the distal colon.

From the available literature, sinus tachycardia and tachy arrhythmias are common with Abrus precatorious poisoning. In this case, we noted sinus bradycardia without symptoms like chest pain, syncope, altered sensorium and decreased urine output. Hence, one should be aware of brady arrhythmias in case of Abrus poisoning which needs some intervention like Injection Atropine and temporary pacemaker in symptomatic patients.

\section{Conclusion}

Abrus precatorious poisoning is not unusual in southern India. Most of the poisoning is of suicidal intention with crushed seeds with presentation of hemorrhagic colitis. Death is usually due to dehydration and hypovolemic shock secondary to large volume blood loss and diarrhea. Early intervention and supportive measures may improve the survival rate and in severe cases, one can try the medications used in severe ulcerative colitis. But the study with optimum number of cases is needed to substantiate this treatment.

\section{Acknowledgment}

I want to thank my co authour for the help and support from the beginning and I want to thank my Residents and medicine colloegues of Sri Venkateswaraa medical college, Puducherry for their support during the course of treatment. I want to thank my family for their moral support.

\section{Funding Information}

The authors have no support or funding to report.

\section{Author's Contributions}

Rajeshkumar Ganesan: Was made the dignosis and planned for the treatment and investigation. 
Rajalakshmi Ettiyan and Rajeshkumar Ganesan: Was collected the material for publication and send for the journal.

\section{Ethics}

This article is original and contains unpublished material. The corresponding author confirms that all of the other authors have read and approved the manuscript and no ethical issues involved.

\section{Reference}

Arena, JM., 1986. Poisoning: Toxicology, Symptoms, Treatments. 5th Edn., Thomas, Springfield, ISBN-10: 0398051437, pp: 1128.

Davies, J.H., 1978. Abrus precatorius (rosary pea). The most common lethal plant poison. J. Fla. Med. Assoc., 65: 188-191. PMID: 641496
Dickers, K.J., S.M. Bradberry, P. Rice, G.D. Griffiths and J.A. Vale, 2003. Abrin poisoning. Toxicol. Rev., 22: 137-142.

Pillay, V.V., P.V. Bhagyanathan, R. Krishnaprasad, R.R. Rajesh and N. Vishnupriya, 2005. Poisoning due to white seed variety of abrus precatorius. J. Assoc. Physicians India, 53: 317-319. PMID: 15987020

Reedman, L., R.D. Shih and O. Hung, 2008. Survival after an intentional ingestion of crushed abrus seeds. West J. Emerg. Med., 9: 157-159.

Shih, R.D. and L.R. Goldfrank, 1998. Plants. In: Goldfrank's Toxicologic Emergencies, Goldfrank, L.R., N.E. Flomenbaum, N.A. Lewin, R.S. Weisman and M.A. Howland et al. (Eds.), Connecticut: Appleton and Lange 6. East Norwalk. 